\title{
A correction method for thermal disturbances induced by thermocouples in a low- conductivity charring material
}

\author{
Ian Pope $\mathrm{a}^{\mathrm{a}^{*}}$, Juan P. Hidalgo ${ }^{\mathrm{a}}$, José L. Torero ${ }^{\mathrm{b}}$ \\ aThe University of Queensland, School of Civil Engineering, Australia, i.pope@uq.edu.au \\ ${ }^{b}$ University College London, Department of Civil, Environmental and Geomatic Engineering, UK
}

*Corresponding author

\begin{abstract}
:
An investigation has been conducted into measurement errors associated with the thermal disturbance created when a thermocouple is inserted perpendicular to a thermal wave in a charring material of low conductivity. Laminated bamboo was used as the embedding material because in-depth temperature measurements are of practical relevance to the characterisation of this potential building material. A combination of experiments and models have been used to determine the error. Experimental results have shown significant differences between the measurements from thermocouples inserted parallel and perpendicular to the isotherms, in terms of both in-depth temperatures and estimated charring rates. Experimental measurements match well with model predictions that accurately represent the thermal disturbance error. This error has been found to decrease over time following a logarithmic trend, and to increase linearly with increasing distance from the heated surface. Models have been used to 'correct' the experimental temperature measurements, and the corrected temperatures have been found to closely approximate the results from thermocouples inserted parallel to the heat wave for inert conditions. This approach may be applied further to correct temperature measurements up to the depth of the char layer for more severe heating conditions.
\end{abstract}

Keywords: heat transfer; temperature measurement; modelling; thermocouple error; laminated bamboo; charring

\section{Introduction}

As a highly renewable natural building material, engineered bamboo has great potential to displace more conventional materials as the construction industry moves to de-carbonise. Laminated bamboo shares many of the benefits of engineered timber products, which are rapidly gaining popularity around the world. As a structural material, laminated bamboo has a high strength-to-weight ratio, potential for pre-fabrication, desirable aesthetic qualities, and is an effective source of carbon sequestration when grown sustainably. Particular advantages of bamboo are its rapid growth rate, coupled with its natural abundance in highly populated developing regions such as Latin America, East Africa and Asia [1].

Bamboo, like timber, is a lignocellulosic material that undergoes physical and chemical processes that cause its mechanical properties to deteriorate at elevated temperatures. One of the leading causes of this degradation is pyrolysis of the constituent polymers - lignin, cellulose and hemicellulose - leaving behind a residual char. Pyrolysis of lignocellulosic materials occurs over a wide range of temperatures, but the base of the char layer is commonly approximated by the 
$300{ }^{\circ} \mathrm{C}$ isotherm [2]. While there are no existing structural fire design standards for engineered bamboo, timber standards assume that charred material has no structural capacity, and this has also been found in a recent study on laminated bamboo [3]. However, it has been observed that mechanical properties can be significantly affected even at temperatures as low as $60{ }^{\circ} \mathrm{C}[2,3]$. Therefore, to accurately assess the structural performance of these materials in fire conditions, it is important to be able to predict the full in-depth temperature profile ahead of the char layer. This requires tailored heat transfer models validated with accurate experimental measurements.

A crucial metric in this validation process is the measurement of internal temperatures by thermocouples inserted through the depth of the studied material. Thermocouple selection is typically driven by experimental conditions and practical constraints. For internal measurements in solid materials, mineral-insulated metal-sheathed (MIMS) thermocouples are often preferred, due to their greater stability, durability and stiffness - allowing them to be easily inserted into narrow holes with reliable contact between the tip and the end of the hole. A typical 'type K' MIMS thermocouple consists of a chromel and an alumel wire surrounded by an electrically insulating material, commonly magnesium oxide $(\mathrm{MgO})$ powder, encased within a protective sheath of Inconel 600 or stainless steel [4]. Wire thermocouples (which are not surrounded by a metal sheath) with exposed junctions have also been recommended for use in laminated timber products, where they may be inlaid between lamellae or inserted into short drilled holes [5]. For timber, Fahrni et al. [5] recommend only inserting thermocouples parallel to the temperature isotherms, to avoid underestimation of charring rates. However, this approach limits the spatial resolution and flexibility of measurement locations that can be achieved. Furthermore, the inlaying of thermocouples is not an option for many materials or specimens. Even amongst laminated materials, the option of placing thermocouples between layers during fabrication may be unavailable, or may even be impossible where the lamination process involves the application of significant heat or pressure. In medium or large-scale experiments, where the distances required to drill holes in from the sample 'side' become excessive, this approach is not viable.

The thermal properties of the constituent materials of a thermocouple often differ greatly from those of the material into which it is embedded. The properties of different sheath, wire, and insulation materials are detailed in Table 1, in comparison with other building materials. The properties of air are also included since a thermocouple inserted into a hole will generally be surrounded by an air gap for part or all of its length. It can be seen from this comparison that the thermal conductivity and diffusivity of sheath and wire materials may be orders of magnitude larger than that of bamboo and timber. The conductivity of the thermocouple insulation is critically dependent upon the solid volume fraction of the mineral powder, with values as low as $0.41 \mathrm{~W} / \mathrm{m} \cdot \mathrm{K}$ reported for a solid volume fraction of $0.58[6]$ or as high as $48.4 \mathrm{~W} / \mathrm{m} \cdot \mathrm{K}$ for a volume fraction of 0.98 [7]. This difference in conductivity between the thermocouple and the surrounding material can create a disturbance in the temperature field near the thermocouple when the sample is subjected to a thermal gradient. Specifically, when a thermocouple is embedded in a way such that it is not aligned parallel with the induced temperature isotherms in the sample, it acts as a thermal bridge between low and high-temperature regions. In this case, the material surrounding the end of the thermocouple in the hotter part of the sample is cooled, while the energy conducted away from this region prematurely heats the material around the cooler end $[5,8,9,10]$. As a result, when the thermocouple tip is located in a region with a higher temperature than the back of the thermocouple, the actual temperature measured at the $\operatorname{tip}\left(T_{T C}\right)$ 
will be less than the 'undisturbed' temperature $\left(T_{u n}\right)$ that would occur at the same location in the material if no thermocouple was present.

Table 1. Thermal Properties of Thermocouple Components and Embedding Materials

\begin{tabular}{|c|c|c|c|c|}
\hline Material (at approx. $300 \mathrm{~K}$ ) & $\begin{array}{l}\text { Conductivity } \\
k(\mathbf{W} / \mathbf{m} \cdot \mathrm{K})\end{array}$ & $\begin{array}{l}\text { Density } \\
\rho\left(\mathrm{kg} / \mathrm{m}^{3}\right)\end{array}$ & $\begin{array}{l}\text { Heat Capacity } \\
C_{P}(\mathrm{~J} / \mathrm{kg} \cdot \mathrm{K})\end{array}$ & $\begin{array}{l}\text { Thermal Diffusivity } \\
\alpha \times 10^{6}\left(\mathrm{~m}^{2} / \mathrm{s}\right)\end{array}$ \\
\hline Inconel 600 [11] & 14.9 & 8470 & 444 & 3.96 \\
\hline Stainless steel 304 [12] & 14.9 & 7900 & 477 & 3.95 \\
\hline Alumel [13] & 29.2 & 8580 & 464 & 7.33 \\
\hline Chromel [13] & 17.3 & 8670 & 426 & 4.68 \\
\hline \multirow{3}{*}{$\begin{array}{l}\text { Magnesium oxide } \\
\text { (solid volume } \\
\text { fraction) }\end{array}$} & 48.4 & 3509 & $922^{2}$ & 14.96 \\
\hline & $0.73^{1}$ & 2334 & $922^{2}$ & 0.34 \\
\hline & $0.41^{1}$ & 2082 & $922^{2}$ & 0.21 \\
\hline Concrete [12] & 1.4 & 2300 & 880 & 0.69 \\
\hline Laminated bamboo [14] & 0.25 & $675^{3}$ & 2260 & 0.16 \\
\hline Softwoods (fir, pine) [12] & 0.12 & 510 & 1380 & 0.17 \\
\hline Air [12] & 0.0263 & 1.1614 & 1007 & 22.49 \\
\hline
\end{tabular}

The magnitude of this temperature disturbance varies over time, and is dependent upon several factors beyond just the thermal properties of each material, including the diameter of the thermocouple and its hole, the contact conditions between the components, and the position of the thermocouple within the embedding material [8]. For the case of a thermocouple inserted from the back of a sample that is being heated on its front surface, in which the thermocouple is aligned perpendicular to the temperature isotherms, this error has been found to be substantial [5, $8,10]$. Side-insertion of thermocouples may not fully eliminate the thermal bridging effect if the heat flow through the material is not one-dimensional, or if the cooler section of the thermocouple that extends out of the sample is still drawing enough heat away from the tip. Sideinsertion can also lead to greater errors in the positioning of the tip of the thermocouple, due to misalignment during drilling. As noted by Reszka [9], a misalignment in the drilling angle of only five degrees for a $50 \mathrm{~mm}$ hole can result in the location of the thermocouple tip being out by as much $4.4 \mathrm{~mm}$ when drilled from the side, compared with only $0.2 \mathrm{~mm}$ if drilled from the back.

Considering the practical circumstances that may constrain the ability to insert thermocouples parallel to the temperature isotherms, it would be ideal to develop a method to 'correct' the measurements of thermocouples inserted from the rear of a sample. Such a method has been proposed by Beck [8] and demonstrated by Woolley and Woodbury [16], however this does not account for charring behaviour, temperature-dependent properties, or imperfect contact along the length of the thermocouple. Furthermore, this requires knowledge of the thermal properties and heat-transfer processes in the embedding material, which may be difficult to determine and is 
often extracted from inverse modelling that relies on the experimental data. This paper presents an experimental study on temperature measurements in laminated bamboo when exposed to different heating conditions using a Mass Loss Calorimeter [17]. Temperature readings are obtained using MIMS type K thermocouples inserted from the side and from the back. This study intends to determine the magnitude of the thermal bridging error, $T_{u n}(t)-T_{T C}(t)$, through the combination of experiments and a model. The model results have been used to explore an approach for correcting this error. Laminated bamboo was used because its thermal properties are sufficiently different to those of the thermocouple to induce a quantifiable error, but also because in-depth temperature measurements are of important practical relevance to the characterisation of this potential building material.

\section{Experimental methods}

Samples used in the experiments were laminated bamboo blocks with dimensions of $120 \times 120 \times$ $100 \mathrm{~mm}$, composed of rectangular-sectioned strips of Phyllostachys pubescens (Moso) bamboo that were bonded together in lamellae with a phenol-formaldehyde resin. The thermal properties of the laminated bamboo are shown in Table 1, and the moisture content was found to be approximately $6.5-7 \%$. The samples were exposed to constant radiant heat fluxes from a Mass Loss Calorimeter in the vertical orientation, as shown in Fig. 1. This configuration was chosen following the approach of Reszka [9] to simplify the boundary conditions by reducing the twodimensional nature of convection and flame heat flux that are present in the horizontal configuration [18]. Heating in the vertical orientation promotes the assumption of a uniform convective film condition based on a vertical flat plate $[9,12]$. Furthermore, since the rear of the sample is exposed to the ambient air, heating of the back of the sample due to conduction from the sample holder is avoided, and the assumption of semi-infinite heating can be sustained for longer. Radiant heat was applied perpendicular to the grain of the bamboo fibres, since this would be the most common scenario for a bamboo structure. The samples were placed on an insulated sample holder on top of the load cell, such that the $120 \times 120 \mathrm{~mm}$ sample surface was aligned with the centre of the cone heater and irradiated at a standard separation distance of $25 \mathrm{~mm}$. The sample dimensions, being larger than the typical $100 \times 100 \mathrm{~mm}$ sample surface [17], were chosen to minimise irradiation or flaming along the sides of the sample, reinforcing the assumption of one-dimensional heating near the centre.

Samples were subjected to constant radiant heat fluxes of 5, 10, 30 or $60 \mathrm{~kW} / \mathrm{m}^{2}$ for a periodof 60 minutes. These heat fluxes were chosen to induce distinct physical and chemical responses in the material, so that these phenomena can be decoupled and evaluated independently in future modelling. The critical heat flux for piloted ignition of laminated Moso bamboo has been found to be approximately $14 \mathrm{~kW} / \mathrm{m}^{2}$ [19], therefore the 5 and $10 \mathrm{~kW} / \mathrm{m}^{2}$ heat fluxes were expected to induce heating regimes that were close to inert, with some minor effects related to moisture migration and evaporation, as well as some pyrolysis near the heated surface at $10 \mathrm{~kW} / \mathrm{m}^{2}$. A heat flux of $30 \mathrm{~kW} / \mathrm{m}^{2}$ is significantly above the critical heat flux for piloted ignition, but below that required for auto-ignition. This heat flux was applied without the use of a pilot igniter, so that the phenomena of charring, cracking, and smouldering combustion could be observed without the additional effects of surface flaming. Finally, $60 \mathrm{~kW} / \mathrm{m}^{2}$ irradiation was applied incombination with a spark igniter, to promote a consistent and early onset of flaming combustion in addition to the previously described phenomena. 

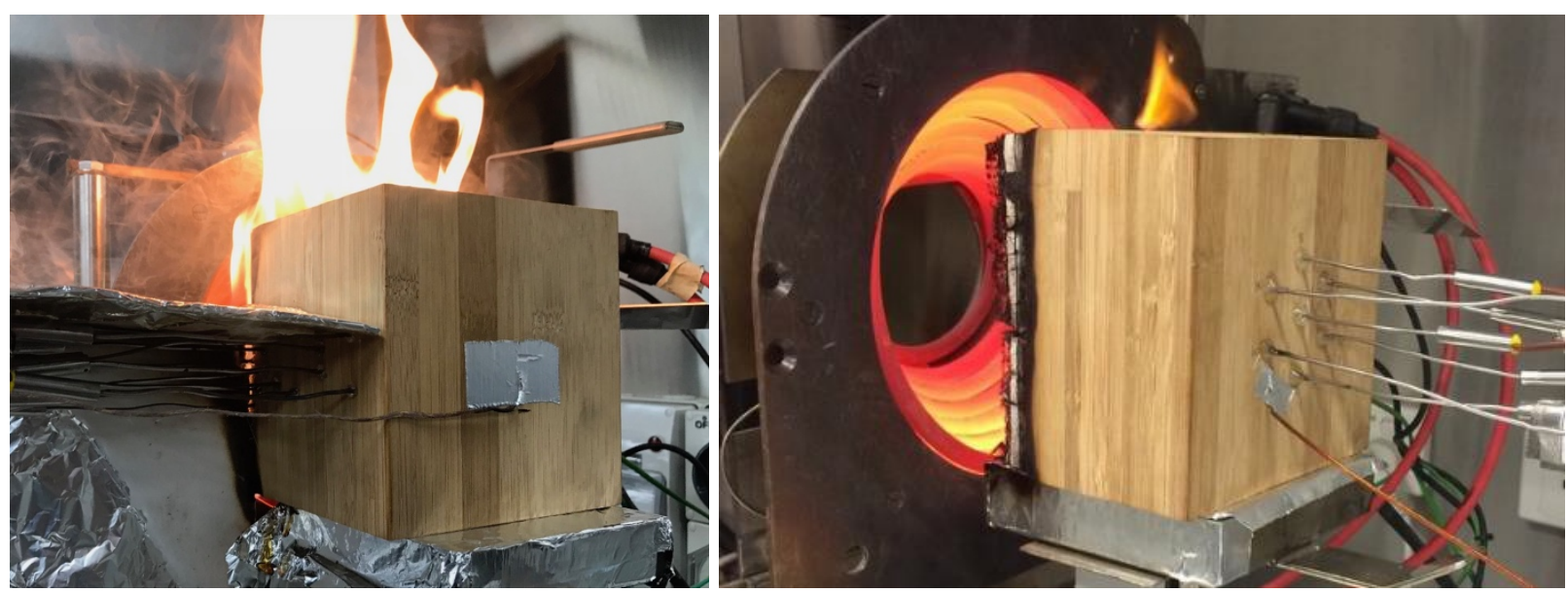

Fig. 1. Samples exposed to $60 \mathrm{~kW} / \mathrm{m}^{2}$ with TCs inserted from the side (left) or the back(right).

For the internal temperature measurements, Inconel-sheathed mineral-insulated K-type thermocouples, with an outer diameter of $1.5 \mathrm{~mm}$, were inserted into $2 \mathrm{~mm}$ diameter holes drilled into the sample by a CNC router. The thermocouples were inserted from either the side of the sample (parallel to the thermal wave) or from the back of the sample (perpendicular to the thermal wave) at distances of 3, 8, 15, 25, 40, 60 and $80 \mathrm{~mm}$ from the heated surface. For the case of side-insertion, the thermocouples were embedded $60 \mathrm{~mm}$ into the sample, with two or three thermocouples placed at each distance from the exposed surface in a staggered alignment as shown in Fig. 2. Results of the side-inserted thermocouples have been presented previously [20]. 518
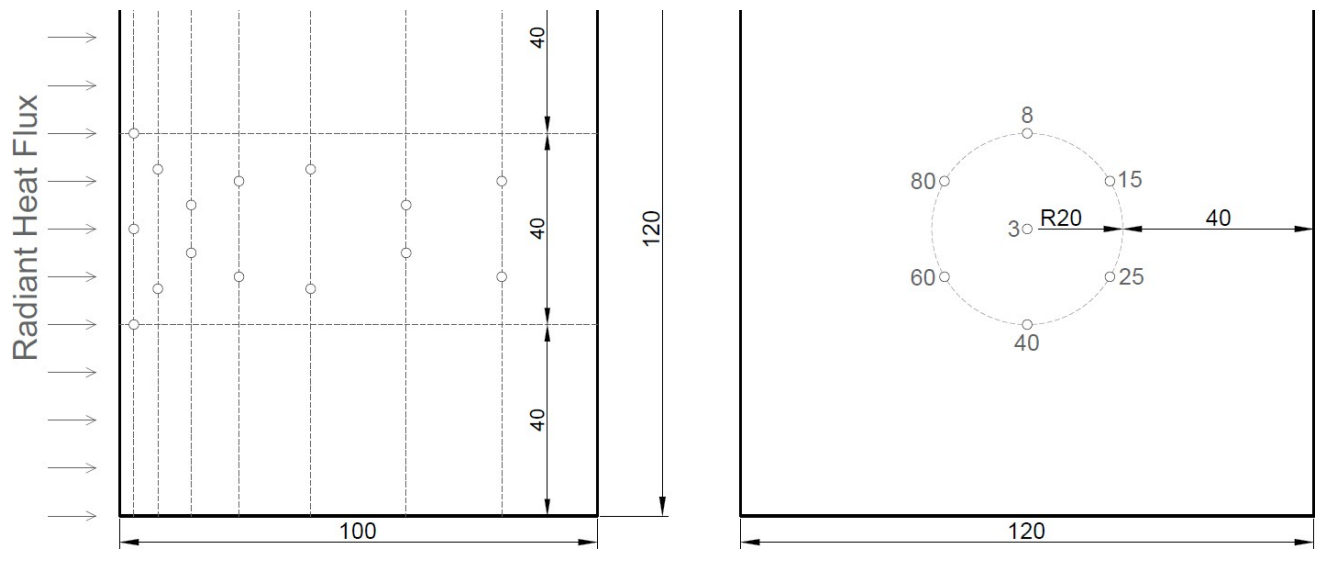

Fig. 2. Spacing and depths $(\mathrm{mm})$ of thermocouple holes in samples in each configuration.

This placement pattern was chosen to avoid lining-up multiple thermocouples in a way that could locally affect the thermal properties of the sample, with at least $10 \mathrm{~mm}$ separation between all thermocouples. Each thermocouple had a $150 \mathrm{~mm}$ long sheath, so the section that extended out from the side of the sample was shielded with ceramic paper and aluminium foil, as shown in 
Fig. 1. For insertion from the rear of the sample, thermocouples at different depths were arranged in a circle of $20 \mathrm{~mm}$ radius around the centre of the sample, as per Reszka [9]. In either case, the tips of all thermocouples were within the middle third of the sample, i.e. less than $20 \mathrm{~mm}$ from the centreline. All of the in-depth thermocouples were glued in place to ensure reliable positioning and contact of the tips with the end of the holes. An additional $0.5 \mathrm{~mm}$ exposedjunction thermocouple was fixed to the back of the sample with aluminium tape, $100 \mathrm{~mm}$ from the heated surface. At least three repetitions were conducted at each heat flux for the backinsertion case, and at least two repetitions for side-insertion (where more thermocouples were inserted at each depth). In this way, a minimum of three separate measurements were taken for all of the in-depth points, with fewer for the rear surface thermocouples, since these were only intended to indicate whether the back of the sample had begun to heat up.

\section{Experimental results and discussion}

In Fig. 3 and Fig. 4, experimental results from thermocouples inserted from the back of each laminated bamboo sample are compared with the corresponding results of side-inserted thermocouples presented previously [20]. Experimental results are presented as averages for each thermocouple position, with standard deviation intervals indicated. It is clear from the experimental results that there is a significant difference between the temperatures recorded with thermocouples inserted in each orientation. For all heat fluxes, measured temperatures rose significantly faster for the thermocouples inserted from the side, parallel to the thermal wave, than from the back. As shown in Fig. 3, this difference is very significant, both quantitatively and qualitatively, although it appears to decrease as the temperatures approach a quasi-steady state. For the shallowest thermocouples in the 30 and $60 \mathrm{~kW} / \mathrm{m}^{2}$ experiments, the measurements from the back and the side appear to converge eventually, however this is due to the fact that the surface of the samples is receding due to oxidation of the char layer. As a result, the thermocouples are eventually exposed, so they are influenced more by the additional convection and radiation at the tip than any disturbance in the solid phase. In Fig. 3, the average temperature histories for each depth have been truncated at the point where the thermocouples became exposed and either fell out (for side-insertion) or recorded unsteady measurements.

The experiments with thermocouples inserted from the back were conducted in ambient temperatures that were between 5 and $10{ }^{\circ} \mathrm{C}$ warmer than for those with thermocouples inserted from the side, so the back-inserted thermocouples initially record higher temperatures. Thus, to make the comparison clearer, results have been presented as the rise in temperature above the initial $\left(T_{T C}-T_{\&}\right)$, rather than the absolute temperature. The progression of the $300^{\circ} \mathrm{C}$ isotherm - assumed to represent the charring front - has been tracked by estimating intermediate values between measurement points through a shape-preserving cubic polynomial interpolation. Similarly, for each of the thermocouple orientations, an isotherm equal to the temperature $35{ }^{\circ} \mathrm{C}$ above ambient has been tracked over time. For an ambient temperature of $25^{\circ} \mathrm{C}$, this would be the isotherm of $60^{\circ} \mathrm{C}$, a temperature at which it has been found that significant mechanical degradation may begin to occur in laminated bamboo and timber [2,3]. Average charring rates have been calculated by dividing the depth of the charring front by the total exposure duration at each point in time. The depths of these isotherms and the calculated charring rates are presented in Fig. 4. Error bars have been calculated based on one standard deviation from the mean of the experimental values, with values between measuring points interpolated as described above. 

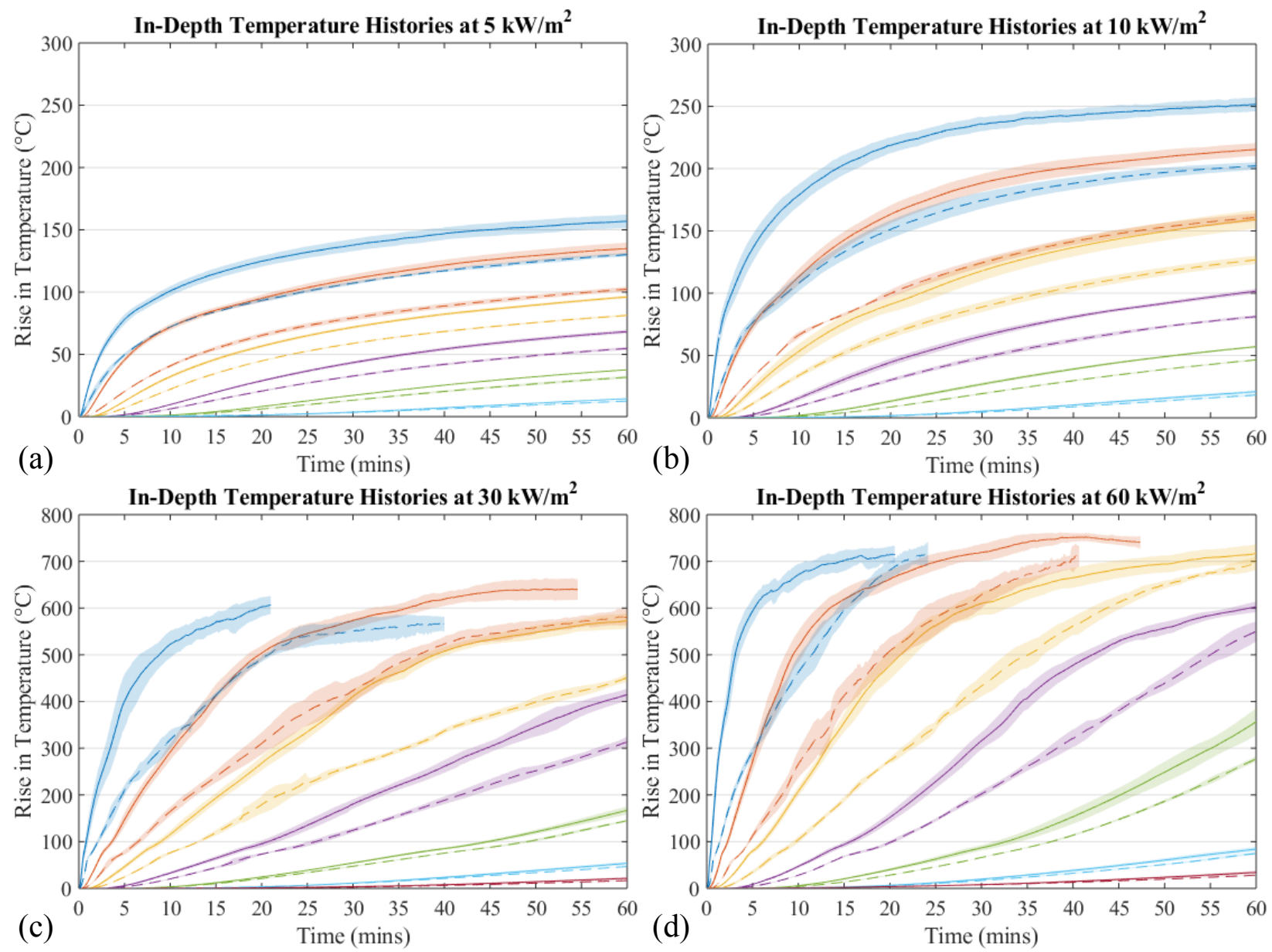

\begin{tabular}{|l}
$-3 \mathrm{~mm}$ (Side) $-8 \mathrm{~mm}$ (Side) $-15 \mathrm{~mm}$ (Side) $-25 \mathrm{~mm}$ (Side) $-40 \mathrm{~mm}$ (Side) $-60 \mathrm{~mm}$ (Side) $-80 \mathrm{~mm}$ (Side) \\
$---3 \mathrm{~mm}$ (Back) $---8 \mathrm{~mm}$ (Back) $---15 \mathrm{~mm}$ (Back) $---25 \mathrm{~mm}$ (Back) $---40 \mathrm{~mm}$ (Back) $---60 \mathrm{~mm}($ Back) $---80 \mathrm{~mm}($ Back $)$
\end{tabular}

Fig. 3. Experimental temperature rise under $5,10,30$ and $60 \mathrm{~kW} / \mathrm{m}^{2}$ with thermocouplesinserted from the side [20] (solid), compared with back-inserted thermocouples (dashed). 575
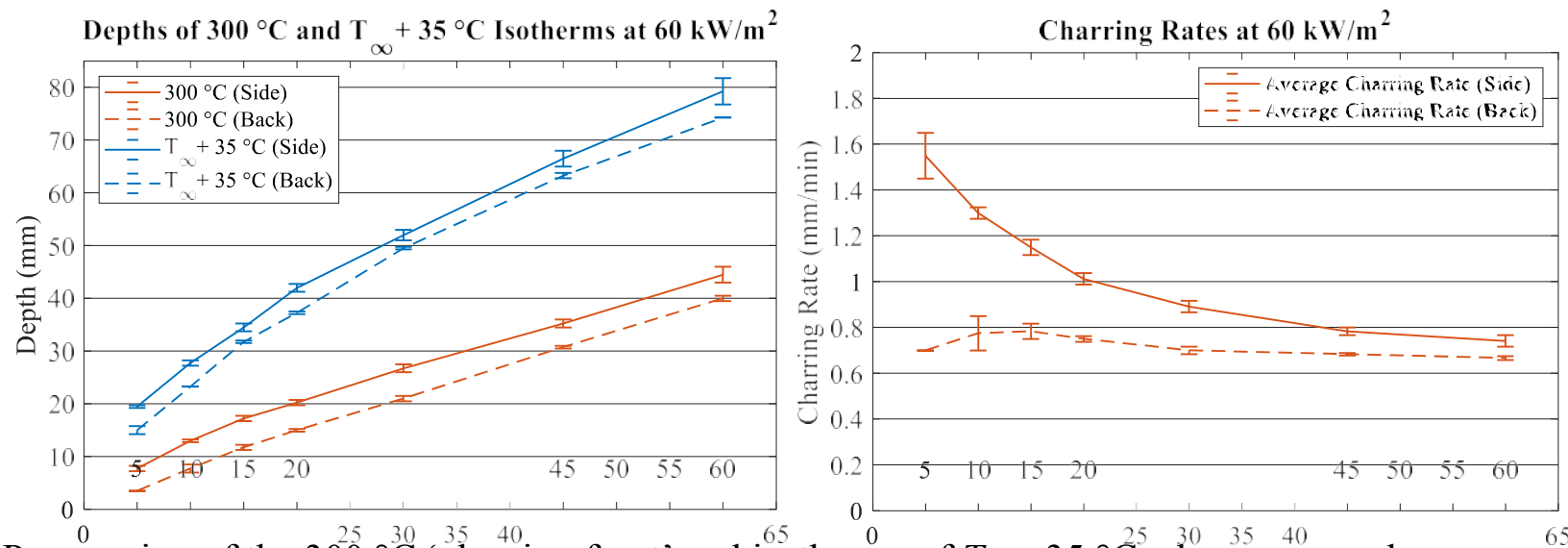

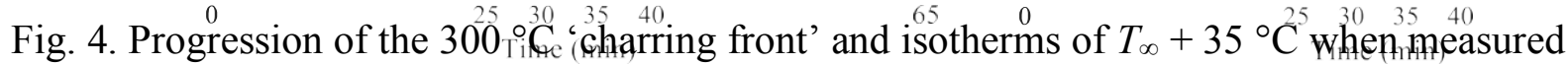
from the side [20] (solid) and from the back (dashed) under $60 \mathrm{~kW} / \mathrm{m}^{2}$. 
As expected, measurements of the charring rate are higher for thermocouples inserted from the side, with the back-inserted thermocouples consistently underestimating the progression of the $300{ }^{\circ} \mathrm{C}$ isotherm by around $5 \mathrm{~mm}$. The charring rate as measured from the side is initially more than double that measured from the back, although these values gradually converge over time. Similarly, the depth at which temperatures have risen by $35^{\circ} \mathrm{C}$ above ambient is always greater when measured from the side, although the difference is reduced in this case. These results suggest that any charring rates and in-depth temperature profiles calculated from the measurements of back-inserted thermocouples will underestimate reality, unless the effect of the thermal disturbance is corrected.

\section{Modelling approach}

For the simplest heating regimes of 5 and $10 \mathrm{~kW} / \mathrm{m}^{2}$, inert heat transfer models were constructed using commercial finite element software to evaluate the disturbance created by the presence of thermocouples inserted by either method. This was achieved by first modelling the transient heat transfer through a solid block of laminated bamboo - in order to calculate the undisturbed temperature profiles - then creating a version that includes an embedded thermocouple. A twodimensional axisymmetric model was created in Abaqus to model the case of a thermocouple inserted from the back of the sample, with the axis of rotational symmetry running down the centre of the thermocouple. For this model, a structured mesh of quadratic, quadrilateral elements was created, as shown in Fig. 5. A three-dimensional model was also created in ANSYS for the case of a thermocouple inserted from the side of the sample. ANSYS was used for the more demanding three-dimensional model due to the greater computational resources that were available for use with this software. Both Abaqus and ANSYS are well validated for inert heat-transfer conditions, so the use of one software over another was not expected to have a significant influence on the results. Due to the geometric constraints of this case, a free mesh of quadratic tetrahedral and hexahedral elements was used, based on the software's adaptive meshing solution. This three-dimensional model is presented in Fig. 6.

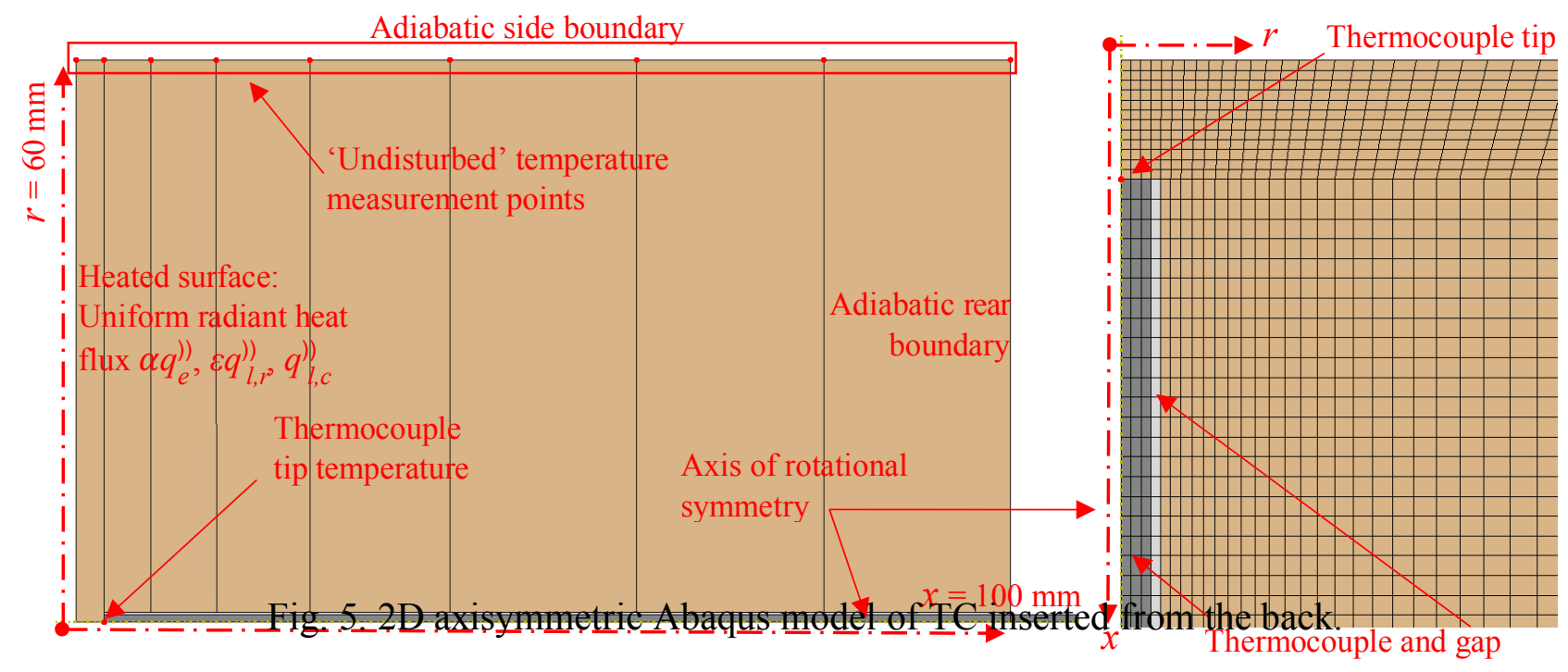



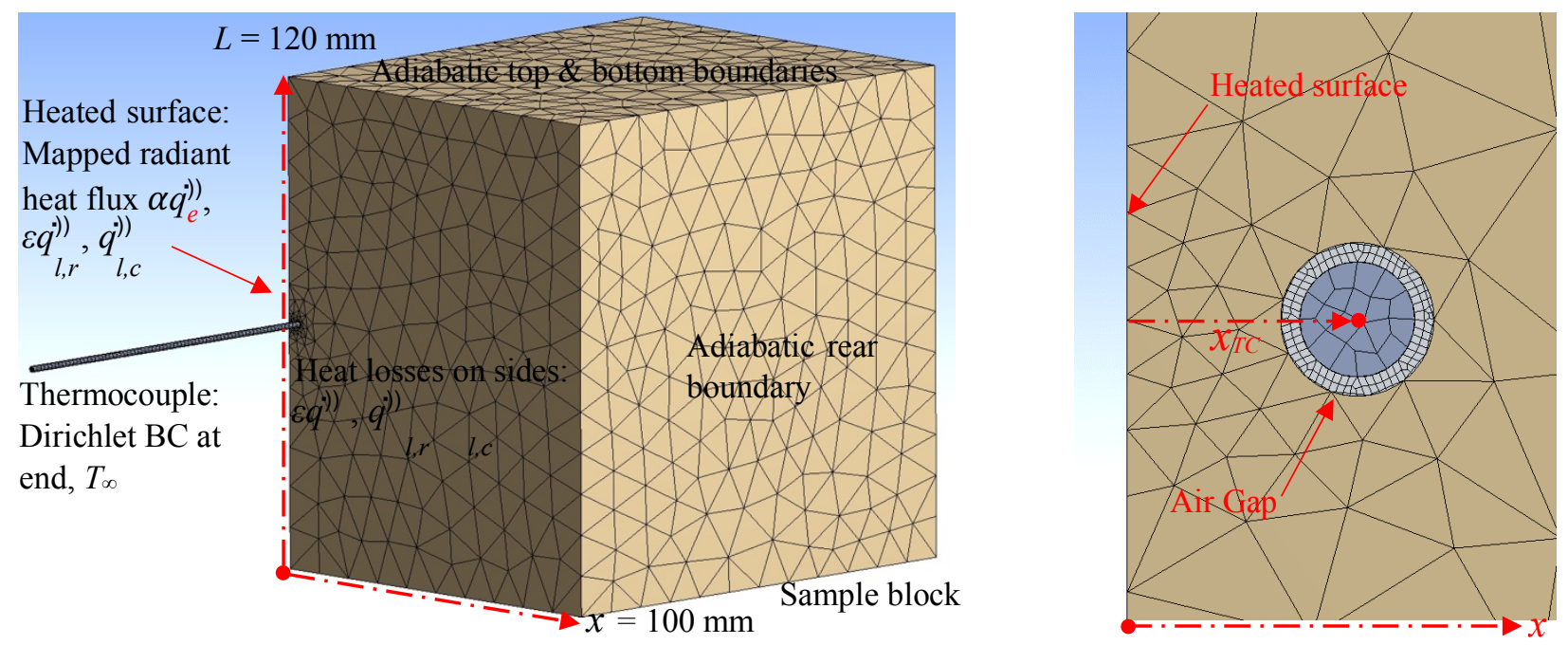

Fig. 6. 3D ANSYS model of TC inserted from the side. Detail of TC mesh shown on the right.

A number of uncertainties surround the thermal properties and interactions included in the above models, which have required some simplifying assumptions. Even amongst mineral-insulated metal-sheathed thermocouples, the properties and geometries of the different components may vary significantly. These include the outside and inside diameters of the sheath and thermocouple wires; the material properties of each component; the contact resistance between the sheath, insulation, and wires; and the exact location of the junction. While the properties of the metallic parts of the thermocouple - the Inconel sheath and the chromel and alumel wires - are well established, the magnesium oxide insulation is more difficult to characterise because it is a powder. Consequently, the properties of the insulation and the efficiency of contact with the other components will be heavily dependent on how densely the powder is packed - a difficult parameter to estimate. As a simplification, the thermocouple was represented in the models by a solid $1.5 \mathrm{~mm}$ diameter cylinder of Inconel with uniform properties. The flat tip of the cylinder was assumed to be in perfect contact with the end of the hole, with air filling the $0.25 \mathrm{~mm}$ gap between the thermocouple and the sides of the hole. Only conduction through the air was modelled, with convection and radiation across the gap neglected. In each case, the length of the model thermocouple was $150 \mathrm{~mm}$, corresponding to the length of the sheath in reality. At the far end of the thermocouple, a constant ambient temperature boundary condition was specified.

Convective and radiative cooling on the unexposed sides of the sample were modelled for the 3D case, since these might induce a temperature gradient across the sample, which could influence the heat conducted through the thermocouples. Finally, based on the results of an experimental heat flux mapping, the applied heat flux for the 3D model was reduced to $92.5 \%$ of the notional value beyond the inner $30 \mathrm{~mm}$ radius, and to $87.5 \%$ beyond the inner $45 \mathrm{~mm}$ radius. A summary of the boundary conditions and input parameters for both models is provided in Table 2 .

For comparison, an additional model was run for a $0.5 \mathrm{~mm}$ diameter thermocouple inserted from the back into a $1.0 \mathrm{~mm}$ diameter hole. In this case, the air gap around the sides of the thermocouple is still $0.25 \mathrm{~mm}$. This geometry was chosen to represent the smallest MIMS thermocouple that can practically be used in many cases, particularly when a long hole must be drilled, so this provides a useful benchmark. 
Table 2. Model Inputs and Boundary Conditions

\begin{tabular}{|c|c|c|c|}
\hline \multicolumn{2}{|c|}{ Input parameter } & Abaqus (back-insertion) & ANSYS (side-insertion) \\
\hline$T_{\infty}$ & Ambient temperature & \multicolumn{2}{|c|}{$24 / 22{ }^{\circ} \mathrm{C}\left(5 / 10 \mathrm{~kW} / \mathrm{m}^{2}\right)$} \\
\hline$T_{0}$ & Initial temperature & \multicolumn{2}{|c|}{$21 / 20^{\circ} \mathrm{C}\left(5 / 10 \mathrm{~kW} / \mathrm{m}^{2}\right)$} \\
\hline$\left.q_{e}^{)}\right)$ & Incident radiation & Uniform, 5 or $10 \mathrm{~kW} / \mathrm{m}^{2}$ & Mapped, 5 or $10 \mathrm{~kW} / \mathrm{m}^{2}$ at centre \\
\hline & Absorptivity/emissivity & \multicolumn{2}{|l|}{0.9} \\
\hline & Emitted radiation & \multicolumn{2}{|l|}{ Stefan-Boltzmann Law } \\
\hline & Convective cooling & \multicolumn{2}{|c|}{ Relationship for a vertical flat plate in quiescent air [12] } \\
\hline \multicolumn{2}{|c|}{ Rear boundary condition } & \multicolumn{2}{|l|}{ Adiabatic } \\
\hline \multirow{2}{*}{\multicolumn{2}{|c|}{$\begin{array}{l}\text { Side boundary conditions } \\
\text { Top/bottom boundary conditions }\end{array}$}} & Adiabatic & $\varepsilon q^{-j)}, q^{j) l} l, r l, c$ \\
\hline & & & Adiabatic \\
\hline \multicolumn{2}{|c|}{ TC end boundary condition } & \multicolumn{2}{|c|}{ Dirichlet boundary condition at $T_{\infty}, 150 \mathrm{~mm}$ from TC tip } \\
\hline \multirow{3}{*}{\multicolumn{2}{|c|}{ Mesh }} & Elements $=11820$ & Elements $=35110$ to 49241 \\
\hline & & Nodes $=36825$ & Nodes $=120955$ to 141895 \\
\hline & & Quadratic, quadrilateral & Quadratic, tetra/hexahedral \\
\hline \multicolumn{4}{|c|}{ Thermal properties } \\
\hline \multicolumn{2}{|c|}{ Laminated bamboo } & \multicolumn{2}{|c|}{ Constant ambient properties as per Table 1} \\
\hline \multicolumn{2}{|l|}{ Air } & \multicolumn{2}{|c|}{ Temperature dependent properties from Incropera \& DeWitt [12] } \\
\hline \multicolumn{2}{|c|}{ Inconel 600} & \multicolumn{2}{|c|}{ Temperature dependent properties [11] } \\
\hline
\end{tabular}

\section{Modelling results and discussion}

The undisturbed temperature results from the centres of the 2D and 3D models agreed closely when benchmarked against each other under equivalent conditions, with a maximum difference in results between corresponding models of less than $5^{\circ} \mathrm{C}$. This confirmed that the 2D axisymmetric model (with uniform surface heat flux and adiabatic side boundary conditions) is equivalent to the 3D model near the centre of the sample. However, temperatures in the 3D model are significantly lower away from the centre due to the attenuation in surface heat flux and the heat losses on the sample sides. In accordance with the experimental measurements, the results of the inert heat transfer modelling at 5 and $10 \mathrm{~kW} / \mathrm{m}^{2}$ also reflected the clear distinction in temperature measurements between the two orientations. Fig. 7 and Fig. 8 show graphical representations of the temperature contours in the vicinity of a thermocouple inserted from either the back or from the side respectively, with the tip of each thermocouple at a depth of $3 \mathrm{~mm}$ behind the heated surface. The thermal bridging effect of the back-inserted thermocouple can be seen clearly, as the laminated bamboo near the tip of the thermocouple is cooled significantly, while the material around the back of the thermocouple is heated prematurely. The impact of the thermocouple on the surrounding temperatures is mostly contained within a radius of $10 \mathrm{~mm}, 65$ suggesting that the spacing between thermocouples recommended by Reszka is appropriate [9].

The insulating effect of the air gap surrounding the thermocouple is also apparent from the change in gradient of isotherms across this gap. This suggests that the size of this gap, and the contact conditions between the thermocouple and the laminated bamboo, are a significant factor in the temperature disturbance. An air gap (or poor thermal contact) near the tip may prevent the thermocouple junction from reaching the same temperature as the surrounding material.

However, the insulating effect of the air gap further from the tip may have the reverse effect, by reducing the energy transferred from the thermocouple to the cooler rear part of the material. 

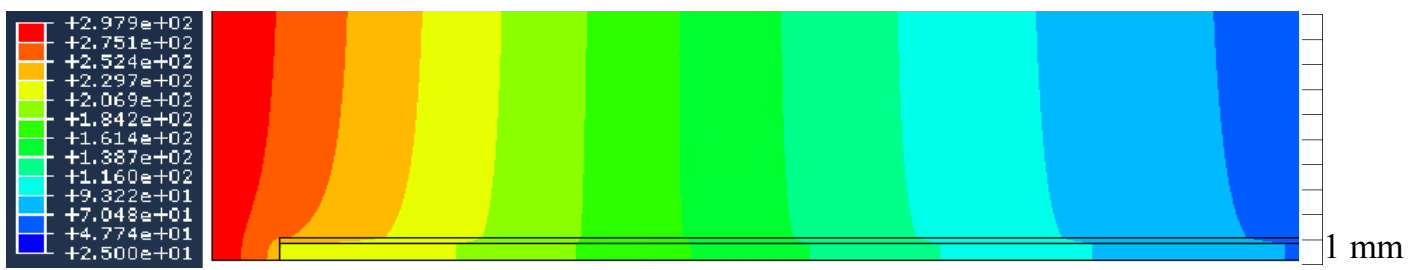

Fig. 7. Graphic from Abaqus model after 60 minutes heating at $10 \mathrm{~kW} / \mathrm{m}^{2}$, showing a distorted temperature field around a back-inserted thermocouple with its tip $3 \mathrm{~mm}$ from the heated surface.

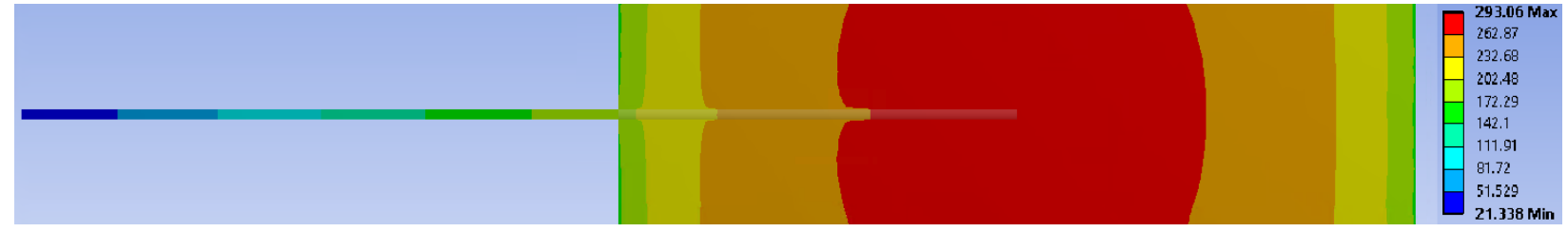

Fig. 8. Graphic from ANSYS model after 60 minutes heating at $10 \mathrm{~kW} / \mathrm{m}^{2}$, with a section through the side-inserted thermocouple at $3 \mathrm{~mm}$ from the heated surface.

In Fig. 8, the effect of the convective and radiative cooling on the sides of the sample are clear, with lower temperatures in the bamboo at the sides of the sample compared with the middle. Nevertheless, the thermocouple inserted from the side appears to be heated sufficiently along its length such that the temperature disturbance created in the bamboo around the tip is minimal. This is confirmed by the numerical output of the 3D ANSYS model, in which the temperatures present at each depth in an undisturbed model (with no thermocouple present) were almost identical to the temperatures predicted to occur at the tip of a side-inserted thermocouple. The maximum difference between the modelled thermocouple and undisturbed temperatures across both heat flux cases was only $5.5^{\circ} \mathrm{C}$, occurring for the thermocouple inserted at $3 \mathrm{~mm}$ from the surface in the $10 \mathrm{~kW} / \mathrm{m}^{2}$ case, with an average difference over the whole time period of only $1.7^{\circ} \mathrm{C}$. For visual clarity, only the undisturbed temperatures from the ANSYS model have been presented in Fig. 10, since these are so close to the modelled thermocouple temperatures.

Fig. 9 shows the results of the Abaqus model for thermocouples inserted from the back. For the most part, the modelled thermocouple temperatures match well with the experimental measurements. However, there is some deviation between the results that may be due to the effect of moisture evaporation and migration that is not captured by the model. For the $3 \mathrm{~mm}$ and $8 \mathrm{~mm}$ thermocouples in the $10 \mathrm{~kW} / \mathrm{m}^{2}$ heating case, there is an obvious inflection in the temperature histories around $100{ }^{\circ} \mathrm{C}$ that is likely due to evaporation, although this becomes less pronounced for the remaining thermocouples and the lower heat flux case for which the heating rate is slower. The experimental temperatures also appear to rise faster than the modelled thermocouple temperatures initially, which may be due to the additional convective heat transfer effect of the migration of moisture in-depth as the heat wave progresses. This effect was also observed for the side-insertion case as shown in Fig. 10. Nonetheless, the modelled thermocouple results match the experiments reasonably well, and are distinctly lower than the modelled undisturbed temperatures over both the transient and quasi-steady periods. In Fig. 10 it can be seen that the experimental results for side-inserted thermocouples match well with the modelled undisturbed temperatures (and the modelled thermocouple temperatures which are almost identical). This supports the suggestion that inserting thermocouples from the side can eliminate the thermal 
bridging error, at least for this material and configuration. Using the modelled thermocouple and undisturbed temperatures at each depth, the relative error in temperature rise above ambient has been calculated as shown in Eq. 1 and presented in Fig. 11.

$$
E(t)=\frac{\left(T_{u n}(t)^{*} T T C(t)\right)}{\left(T_{u n}(t)^{*} T_{\infty}\right)}
$$

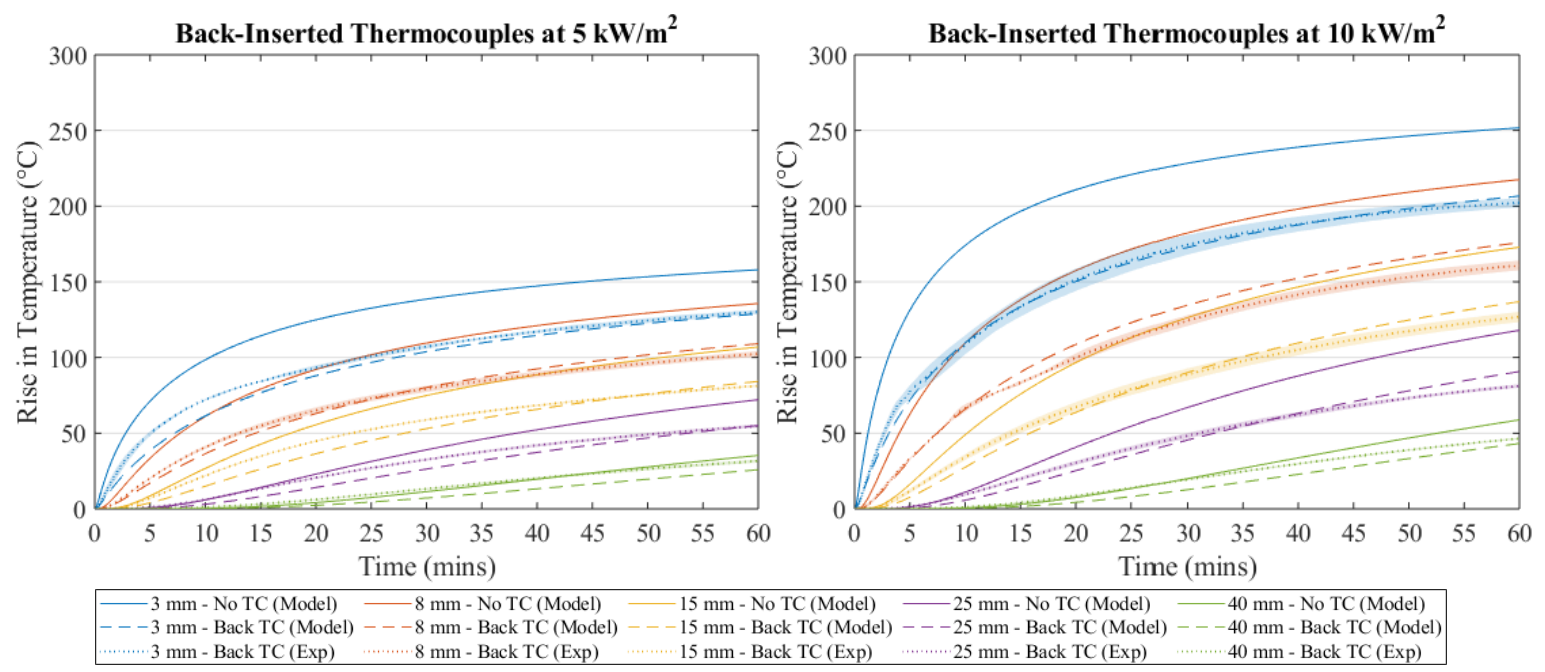

Fig. 9. Results of 5 and $10 \mathrm{~kW} / \mathrm{m}^{2}$ models for undisturbed temperatures (solid) and modelled back-inserted thermocouples (dashed) compared with experimental results (dotted).

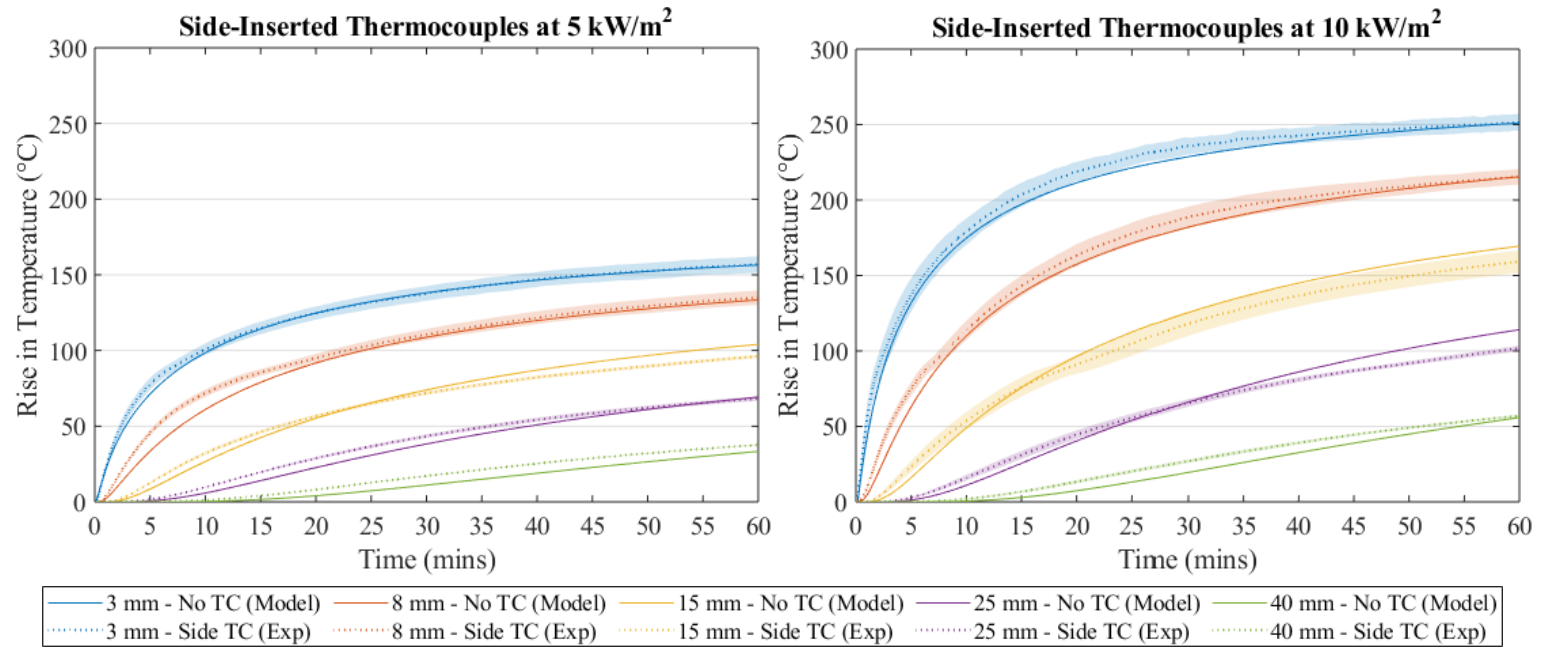

Fig. 10. Results of 5 and $10 \mathrm{~kW} / \mathrm{m}^{2}$ models for undisturbed temperatures (solid) compared with experimental results for side-inserted thermocouples [20] (dotted).

The relative error peaks initially as the thermal wave first reaches each depth, but then decreases over time closely following a logarithmic trend, which can be seen from the regression curves plotted in Fig. 11(a). The data diverges slightly from the logarithmic relationship for the earliest times, but overall the $\mathrm{R}^{2}$ values of the regressions shown are all greater than 0.97 . As shown in Fig. 11(b), errors appear to increase in a strongly linear manner with depth behind the heated surface. This suggests that the relationship between error and depth may be predictable, based on 
a function of the distance between measurement points, and the thermal properties of the different materials. If this relationship can be quantified in future studies, then a known or calculated error at one point in the material could be extrapolated to find the error at another point. The equations of the individual regression functions in Fig. 11 vary slightly with depth (a) and time (b), suggesting that there are interdependencies between these relationships that must be investigated further before a more generalised function can be developed. Fig. 11(a) also shows how the error induced by the $0.5 \mathrm{~mm}$ diameter thermocouple is considerably smaller, but still significant - up to $50 \%$ at the earliest times (when absolute temperature differences are relatively small), and still in the order of $10-15 \%$ after an hour.

The magnitude of the external heat flux appears to have only a very limited impact on the error percentage. In order to evaluate the influence of the net surface heat flux on the relative errors, additional models were run with no convective or radiative cooling, so that the external heat flux represented a net heat flux. While these models were run with net heat fluxes of different magnitudes, no difference in the relative errors was observed between them. This suggests that the absolute magnitude of the net surface heat flux has no influence on the errors, but the way that the net heat flux changes over time does. For example, constant net heat fluxes of 1, 5 and $10 \mathrm{~kW} / \mathrm{m}^{2}$ will all have the same error as calculated by Eq. 1, however if these net heat fluxes were not constant but varied over time differentially, they would induce different errors. This effect explains the slight difference in errors between the 5 and $10 \mathrm{~kW} / \mathrm{m}^{2}$ heating cases seen in Fig. 11(b), since the radiative and convective cooling on the surface are temperature-dependent.
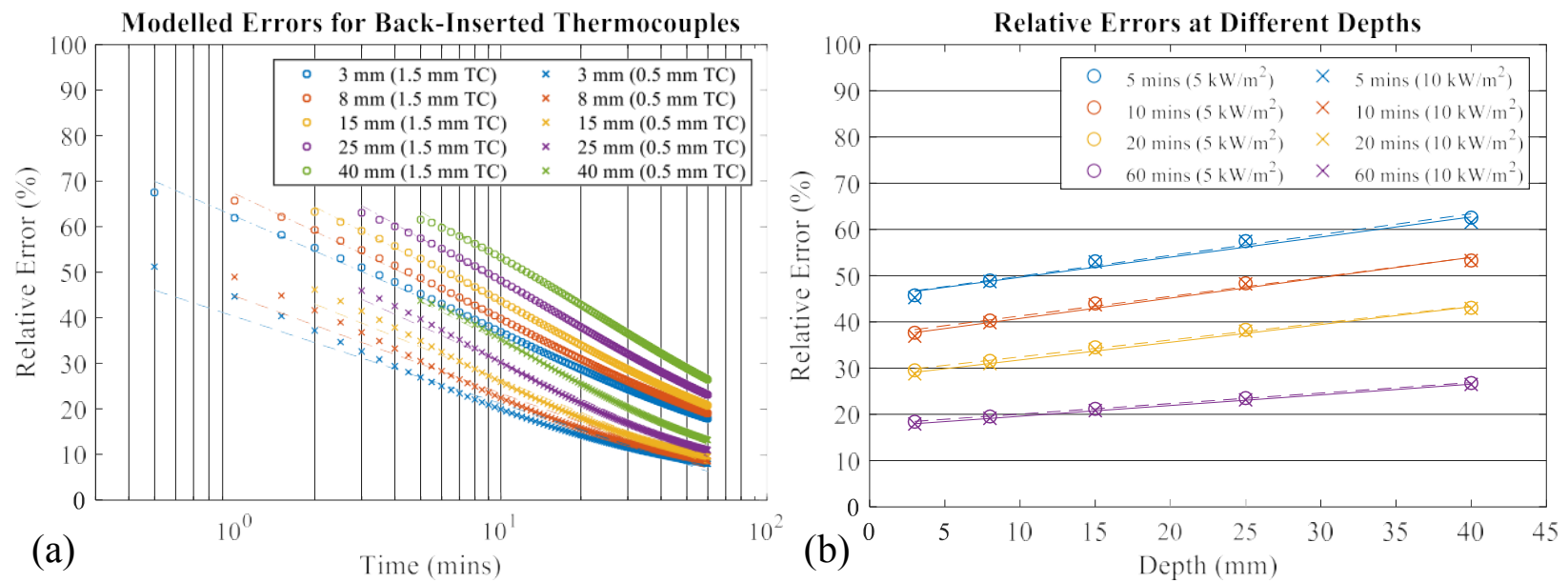

Fig. 11. Relative errors for back-inserted thermocouples over time at different depths, from Abaqus models (a) of 1.5 and $0.5 \mathrm{~mm} \mathrm{TCs}$, and (b) at $5 \mathrm{~kW} / \mathrm{m}^{2}$ (dashed) and $10 \mathrm{~kW} / \mathrm{m}^{2}$ (solid).

In order to evaluate how well the models account for the thermal bridging effect, the calculated errors have been used to estimate 'corrected' temperatures for the thermocouples inserted from the back. By rearranging Eq. 1, this correction uses the errors calculated from the models and the experimentally measured thermocouple temperatures to calculate the undisturbed temperature rise above ambient. The results of this analysis are shown in Fig. 12, in comparison with the modelled undisturbed temperature rise and the temperature rise measured from the experiments with side-inserted thermocouples. The corrected thermocouple temperatures are much closer to both the undisturbed temperatures and the measurements of the side-inserted thermocouples. This 
suggests that the model of back-inserted thermocouples, despite its simplicity, is accurately estimating the thermal disturbance created in this case. The deviations between the corrected and undisturbed temperatures are likely due to the model failing to capture the effects of moisture.

This correction technique requires a model with well-defined material properties and boundary conditions, which would seem to limit its applicability to inert heating regimes. However, if the thermal properties and heat-transfer mechanisms in the material ahead of the charring front are similar to those corresponding to inert heating, it may be possible to apply the same correction method to the measured temperatures up to the point of charring. In this way, a more accurate estimate of the charring rate and the in-depth temperature profile behind the char layer may be derived. Moreover, since it has been observed that the magnitude of the surface heat flux does not have a significant effect on the error, it may be possible to apply corrections calculated for lower heat fluxes to the experimental results for higher heat fluxes. To explore this possibility, the errors calculated from the inert $10 \mathrm{~kW} / \mathrm{m}^{2}$ model were used to correct the experimental results from 30 and $60 \mathrm{~kW} / \mathrm{m}^{2}$, as shown in Fig. 13.

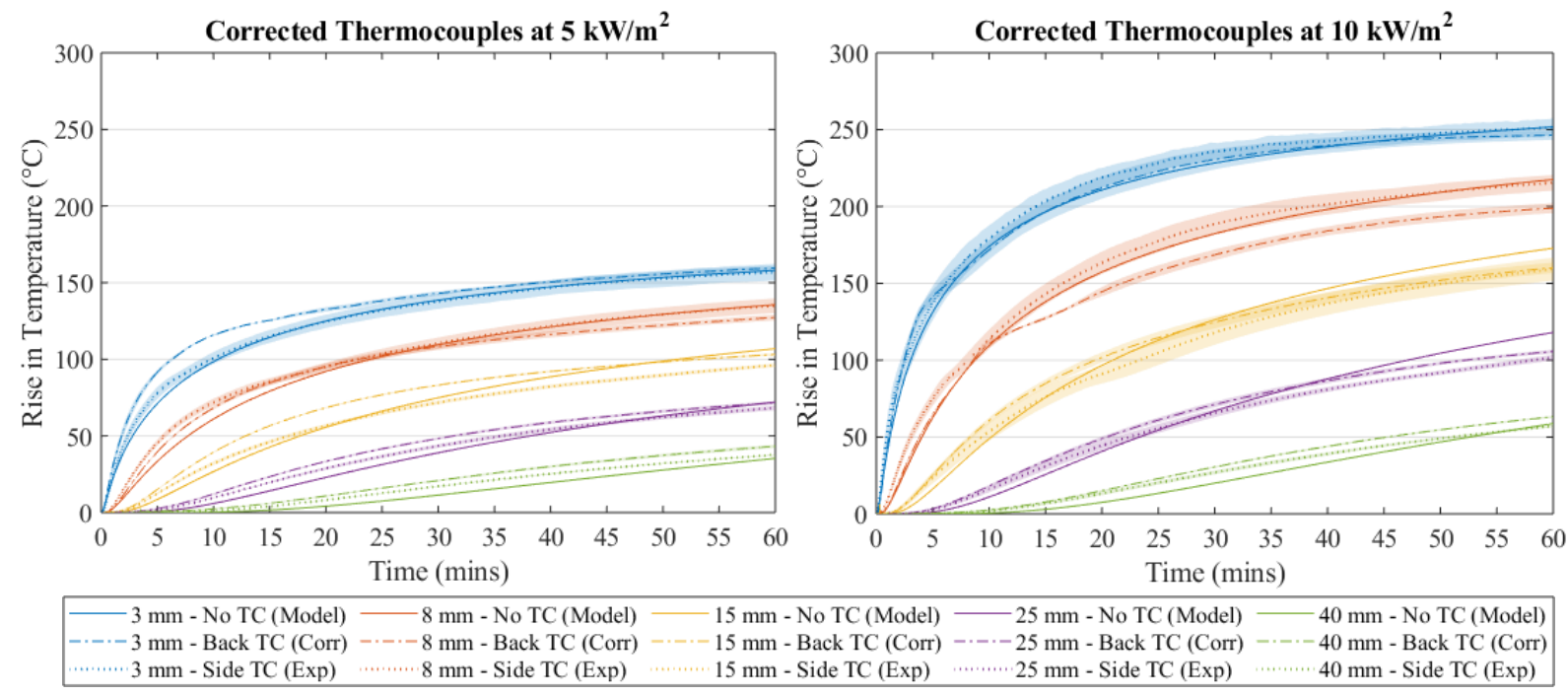

Fig. 12. 'Corrected' results for back-inserted thermocouples (dash-dot) compared with modelled undisturbed temperatures (solid) and experimental side-inserted results [20] (dotted).
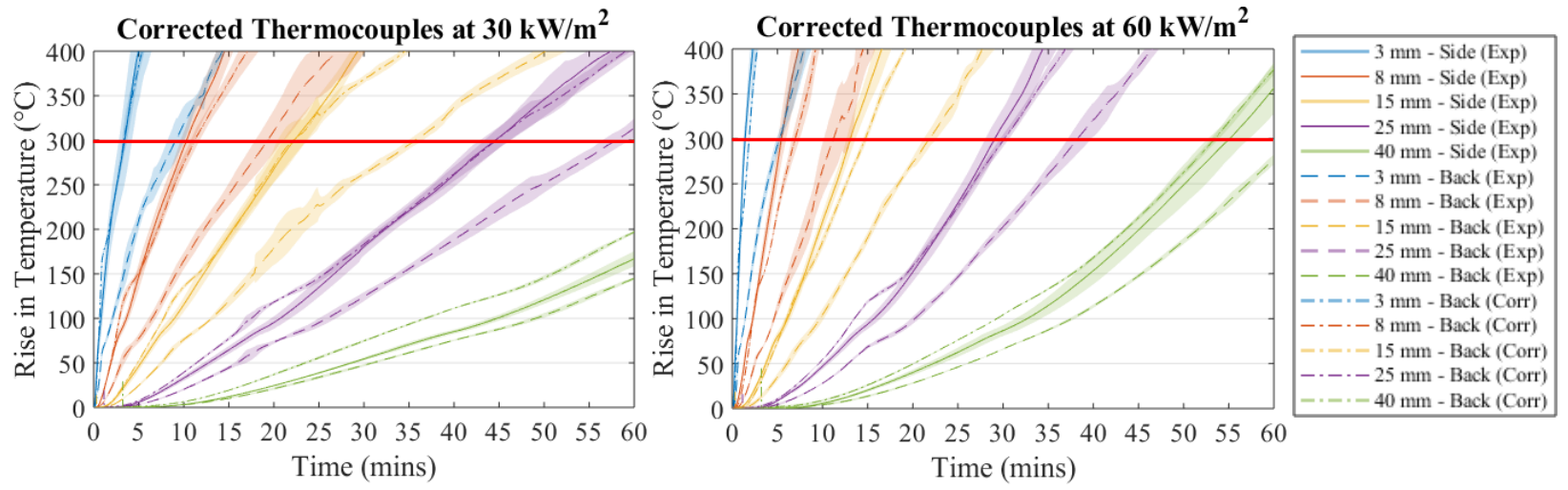

Fig. 13. 'Corrected' back-inserted TC results (dash-dot) for 30 and $60 \mathrm{~kW} / \mathrm{m}^{2}$, compared with experimental side-inserted results (solid) and uncorrected back-inserted results (dashed) [20]. 
Above $350{ }^{\circ} \mathrm{C}$, the 'corrected' temperatures begin to deviate significantly from the side-inserted measurements, due to the changing material properties and regression of the char layer. However, the calculated temperatures below $300{ }^{\circ} \mathrm{C}$ match fairly well with the side-inserted thermocouple results. Therefore, this approach may be reasonable within the scope of estimating in-depth temperatures ahead of the charring front. This boundary of applicability is demarcated by the red dotted lines in Fig. 13.

\section{Conclusions}

This paper has presented an investigation into the measurement error associated with the thermal disturbance created when a thermocouple is inserted perpendicular to a thermal wave in a charring material of much lower conductivity. Laminated bamboo was used as the embedding material because its thermal properties are sufficiently different to those of the thermocouple to induce a quantifiable error, and because in-depth temperature measurements are of important practical relevance to the characterisation of this potential building material. A combination of experiments and models have been used to determine the error, by comparison with undisturbed model temperatures and measurements from thermocouples inserted parallel to the thermal wave. Experimental results have shown significant differences between the measurements from thermocouples inserted parallel and perpendicular to the isotherms, in terms of both in-depth temperatures and estimated charring rates. These experimental measurements at 5 and $10 \mathrm{~kW} / \mathrm{m}^{2}$ match well with model predictions that accurately represent the thermal disturbance error. This error has been found to decrease over time with a logarithmic relationship, and to increase linearly with increasing distance from the heated surface. Modelling of a much smaller diameter thermocouple has shown that the thermal disturbance is greatly reduced in this case, but the induced error may still be significant and require correction.

In certain experimental scenarios it is not practically viable to insert thermocouples parallel to the heat wave, so a method for correcting this thermal disturbance is required. The errors calculated from the models have been used to 'correct' the experimental temperature measurements, and the corrected temperatures have been found to closely approximate the results from thermocouples inserted parallel to the heat wave for inert heating conditions. Since the magnitude of the imposed heat flux was found to be only weakly related to the percentage of error, the errors calculated for the near-inert heating regime of $10 \mathrm{~kW} / \mathrm{m}^{2}$ were further applied to higher heat fluxes that induce charring. These 'corrected' temperature measurements matched closely with side-inserted thermocouples until temperatures at each depth reached a range in which charring becomes significant. This demonstrates the potential of simple heat transfer models to improve the accuracy of experimentally measured charring rates and temperature profiles ahead of the charring front, while accounting for specific geometries, contact conditions and thermal boundaries. This provides a useful approach for quantifying structural degradation in laminated bamboo and timber, for which only the temperatures ahead of the charring front are relevant.

\section{Acknowledgements}

The authors would like to thank Moso International BV for providing the laminated bamboo for this project, and the financial support provided by the Worshipful Company of Engineers through the Sir Peter Gadsden Britain Australia Travel Award 2018. The authors are also grateful for the assistance of Jeronimo Carrascal, Mateo Gutierrez, Angela Solarte and the rest of UQ Fire. 


\section{References}

[1] Sharma, B, Gatoo, A, Bock, M \& Ramage, M 2015, 'Engineered bamboo for structural applications', Construction and Building Materials, vol. 81, pp. 66-73.

[2] White, RH 2016, 'Analytical Methods for Determining Fire Resistance of Timber Members', in Hurley, MJ et al. (eds), SFPE Handbook of Fire Protection Engineering, Springer, New York. [3] Gutierrez Gonzalez, M, Madden, J \& Maluk, C 2018, 'Experimental study on compressive and tensile strength of bamboo at elevated temperatures', 2018 World Conference on Timber Engineering, WCTE 2018 Committee, Seoul, Republic of Korea, 20-23 August.

[4] CENELEC 2016, Mineral insulated metal-sheathed thermocouple cables and thermocouples, IEC 61515:2016, European Committee for Electrotechnical Standardization, Brussels.

[5] Fahrni, R, Schmid, J, Klippel, M \& Frangi, A 2018, 'Correct temperature measurements in fire exposed wood', 2018 World Conference on Timber Engineering, WCTE 2018 Committee, Seoul, Republic of Korea, 20-23 August.

[6] Godbee, HW \& Ziegler, WT 1966, 'Thermal conductivities of $\mathrm{MgO}, \mathrm{Al}_{2} \mathrm{O}_{3}$, and $\mathrm{ZrO}_{2}$ powders to $850^{\circ} \mathrm{C}$, I. Experimental', Journal of Applied Physics, vol. 37, no. 1, pp. 40-55.

[7] Powell, RW, Ho, CY, Liley, PE 1966, National Standard Reference Data Series - National Bureau of Standards 8, Thermal Conductivity of Selected Materials, U.S. Government Printing Office, Washington.

[8] Beck, JV 1962, 'Thermocouple temperature disturbances in low conductivity materials', Journal of Heat Transfer, vol. 84, no. 2, pp. 124-131.

[9] Reszka, P 2008, 'In-depth temperature profiles in pyrolysing wood', PhD thesis, The University of Edinburgh, Edinburgh.

[10] Laschütza, T 2017, 'Numerical and experimental investigation of a Thin Skin Calorimeter (TSC)', MSc Dissertation, The University of Edinburgh, Edinburgh.

[11] Special Metals Corporation 2008, INCONEL alloy 600, viewed 15 July 2019, $<$ http://www.specialmetals.com/assets/smc/documents/alloys/inconel/inconel-alloy-600.pdf $>$. [12] Incropera, FP, DeWitt, DP, Bergman, TL \& Lavine, AS 2007, Fundamentals of heat and mass transfer, 6th edn, John Wiley \& Sons, Hoboken NJ.

[13] Sundqvist, B 1992, 'Thermal diffusivity and thermal conductivity of Chromel, Alumel, and Constantan in the range 100-450 K', Journal of Applied Physics, vol. 72, no. 2, pp. 539-545.

[14] Solarte, A, Numapo, J, Hidalgo, JP \& Torero, JL 2019, 'Flame spread in laminated bamboo structures'. Proceedings of the Ninth International Seminar on Fire and Explosion Hazards (ISFEH9). Saint-Petersburg Polytechnic University Press, Saint Petersburg, Russia, pp. 755-766. [15] NIST 2018, Magnesium oxide, U.S. Department of Commerce, viewed 15 July 2019, $<$ https://webbook.nist.gov/cgi/inchi?ID=C1309484\&Type=JANAFS\&Plot $=$ on $>$.

[16] Woolley, JW \& Woodbury, KA 2011, 'Thermocouple data in the inverse heat conduction problem', Heat Transfer Engineering, vol. 32, no. 9, pp. 811-825.

[17] ISO 1993, Fire Tests Reaction to Fire Part 1: Rate of Heat Release from Building Products (Cone Calorimeter Method), ISO 5660-1:1993, International Organization for Standardization, Geneva [18] McCoy, CG, Tilles, JL, Stoliarov, SI 2019, 'Empirical model of flame heat feedback for simulation of cone calorimetry', Fire Safety Journal, vol. 103, pp. 38-48.

[19] Solarte, A, Hidalgo, JP \& Torero, JL 2018, 'Flammability studies for the design of fire-safe bamboo structures', 2018 World Conference on Timber Engineering, WCTE 2018 Committee, Seoul, Republic of Korea, 20-23 August.

[20] Pope, I, Hidalgo, JP, Osorio, A, Maluk, C \& Torero, JL 2019, 'Thermal behaviour of laminated bamboo structures under fire conditions', Fire and Materials,

pp. 1-10, https://doi.org/10.1002/fam.2791 